\title{
Presynaptic Control of Corticostriatal Synapses by Endogenous GABA
}

\author{
Christopher Logie, ${ }^{1}$ Vincenza Bagetta, ${ }^{2}$ and Enrico Bracci $^{3}$ \\ ${ }^{1}$ Faculty of Life Sciences, University of Manchester, Manchester M13 9PT, United Kingdom, ${ }^{2}$ Laboratorio di Neurofisiologia, Fondazione Santa Lucia, 00143 \\ Rome, Italy, and ${ }^{3}$ Department of Psychology, The University of Sheffield, Sheffield S10 2TP, United Kingdom
}

Corticostriatal terminals have presynaptic $\mathrm{GABA}_{\mathrm{B}}$ receptors that limit glutamate release, but how these receptors are activated by endogenous GABA released by different types of striatal neurons is still unknown. To address this issue, we used single and paired whole-cell recordings combined with stimulation of corticostriatal fibers in rats and mice. In the presence of opioid, $\mathrm{GABA}_{\mathrm{A}}$, and $\mathrm{NK}_{1}$ receptor antagonists, antidromic stimulation of a population of striatal projection neurons caused suppression of subsequently evoked EPSPs in projection neurons. These effects were larger at intervals of $500 \mathrm{~ms}$ than 1 or $2 \mathrm{~s}$, and were fully blocked by the selective GABA receptor antagonist CGP 52432. Bursts of spikes in individual projection neurons were not able to inhibit evoked EPSPs. Similarly, spikes in fast spiking interneurons and low-threshold spike interneurons failed to elicit detectable effects mediated by $\mathrm{GABA}_{\mathrm{B}}$ receptors. Conversely, spikes in individual neurogliaform interneurons suppressed evoked EPSPs, and these effects were blocked by CGP 52432. These results provide the first demonstration of how $\mathrm{GABA}_{\mathrm{B}}$ receptors are activated by endogenous GABA released by striatal neuronal types.

\section{Introduction}

The striatum is the largest nucleus of the basal ganglia and is critically involved in motor control, action selection, and reinforcement learning (Alexander and Crutcher, 1990; Graybiel et al., 1994). Massive projections target the striatum from the cortex and the thalamus, forming glutamatergic synapses mainly on the dendrites of the medium spiny neurons (MSNs), the striatal projection cells (Bolam et al., 2000). As far as striatal neurons are concerned, GABA is by far the major neurotransmitter, being expressed by all MSNs and at least three well characterized classes of interneurons (Tepper and Bolam, 2004; Ibáñez-Sandoval et al., 2011). The axon collaterals of MSNs form symmetric GABAergic synapses with other MSNs. Paired recording experiments have shown that these synapses elicit $\mathrm{GABA}_{\mathrm{A}}$ receptor-mediated IPSPs in the postsynaptic neuron (Tunstall et al., 2002; Tepper et al., 2008). Fast spiking interneurons (FSIs), low-threshold spike interneurons (LTSIs), and neurogliaform interneurons (NGFIs), also form functional synapses with MSNs (Tepper et al., 2008; Ibáñez-Sandoval et al., 2011; Szydlowski et al., 2013). GABA receptors are ubiquitous metabotropic receptors that mediate presynaptic and postsynaptic inhibition throughout the brain (Chalifoux and Carter, 2011). However, their role in mediating communication among striatal neurons is still poorly under-

Received May 23, 2013; revised July 30, 2013; accepted Aug. 19, 2013.

Author contributions: C.L. and E.B. designed research; C.L. and V.B. performed research; C.L. and V.B. analyzed data; C.L. and E.B. wrote the paper.

This study was funded by the Wellcome Trust (Grant no. 084706/Z/08/Z).

The authors declare no competing financial interests.

Correspondence should be addressed to Dr Enrico Bracci, Department of Psychology, The University of Sheffield,

Western Bank, Sheffield, S10 2TP, UK. E-mail: e.bracci@manchester.ac.uk.

DOI:10.1523/JNEUROSCI.2304-13.2013

Copyright $\odot 2013$ the authors $\quad 0270-6474 / 13 / 3315425-07 \$ 15.00 / 0$ stood, as their activation by synaptically released GABA has not been demonstrated. In the striatum, $\mathrm{GABA}_{\mathrm{B}}$ receptors are found on GABA terminals, on glutamate terminals of cortical and thalamic origin and on the dendrites of MSNs (Lacey et al., 2005). Despite the presence of postsynaptic receptors, application of exogenous $\mathrm{GABA}_{\mathrm{B}}$ agonists does not produce measurable effects on MSN membrane properties. On the other hand, exogenous activation of $\mathrm{GABA}_{\mathrm{B}}$ receptors strongly suppresses glutamatergic inputs onto MSNs acting through a presynaptic mechanism (Calabresi et al., 1991; Nisenbaum et al., 1993). Whether and how these presynaptic $\mathrm{GABA}_{\mathrm{B}}$ receptors can be activated by endogenous GABA released by different striatal neurons remains to be established. Using protocols combining paired recording with stimulation of corticostriatal fibers, we have recently shown that an important modality of communication for the striatal neurons consists in the activation of presynaptic receptors located on glutamatergic terminals impinging on MSNs (Pakhotin and Bracci, 2007; Blomeley et al., 2009; Blomeley and Bracci, 2011). Here, we used similar procedures to unravel how presynaptic $\mathrm{GABA}_{\mathrm{B}}$ receptors are activated by different GABAergic striatal neurons.

\section{Materials and Methods}

Experiments were conducted on male and female P14-P21 Sprague Dawley rats and P14-P21 BAC transgenic mice heterozygous for the attachment of the NPY promoter to humanized renilla GFP (BAC-npy; stock no. 006417; The Jackson Laboratory). In these mice, NPY-GFP is expressed in the striatum by LTSIs and NGFIs (Partridge et al., 2009; Ibáñez-Sandoval et al., 2011). Rats and mice underwent cervical dislocation in accordance with the United Kingdom Animals (Scientific Procedures) Act, 1986. Following rapid brain removal, parasagittal slices (200-250- $\mu \mathrm{m}$-thick) were cut using a vibroslicer (Campden Instruments) in a cutting solution of artificial CSF (ACSF; concentrations of the following in mM: $124 \mathrm{NaCl}, 2 \mathrm{KCl}, 1 \mathrm{MgSO}_{4}, 1.25 \mathrm{KH}_{2} \mathrm{PO}_{4}, 2 \mathrm{CaCl}_{2}$, 
$26 \mathrm{NaHCO}_{3}$, and 10 glucose) containing $1 \mathrm{~mm}$ kynurenic acid, maintained at $25^{\circ} \mathrm{C}$ and oxygenated with $95 \% \mathrm{O}_{2}, 5 \% \mathrm{CO}_{2}$ gas. After cutting, slices were maintained for at least $30 \mathrm{~min}$ in ACSF without kynurenic acid. During recording, slices were superfused with ACSF (1.5-2 ml/ min) and visualized using $10 \times$ and $40 \times$ water-immersion objectives using infrared and differential interference contrast microscopy.

NPY-expressing neurons were identified through epifluorescent excitation with a mercury lamp (Olympus U-RFL-T) in conjunction with standard GFP filters. Fluorescent neurons were identified as LTSIs or NGFIs based on their distinctive electrophysiological properties (IbáñezSandoval et al., 2011). MSNs and FSIs were also identified based on their electrophysiological features (Bracci et al., 2003; Blomeley and Bracci, 2011).

Whole-cell recordings of striatal neurons were conducted using glass pipettes filled with intracellular solution (in mM: $120 \mathrm{~K}$-gluconate, 20 $\mathrm{KCl}, 0.04$ EGTA, 12 HEPES, $2 \mathrm{MgCl}_{2}, 4 \mathrm{Na}_{2} \mathrm{ATP}$, and $0.4 \mathrm{NaGTP}$, adjusted to $\mathrm{pH} 7.3$ with $\mathrm{KOH})$. Pipette resistance was 3-7 M $\Omega$. Recordings were performed in current-clamp configuration using bridge amplifiers (BA-1S, BA-01×; NPI connected to a micro1401 analog-digital converted ( $5 \mathrm{kHz}$ sampling) driven by Signal software. Input resistance was monitored with small negative current injections.

Single-recording experiments were conducted in the continuous presence of antagonists of the following receptors: $\mathrm{GABA}_{\mathrm{A}}$ (100 $\mu \mathrm{M}$ picrotoxin), D1 (10 $\mu \mathrm{M}$ SCH 23390 hydrochloride), D2 (3 $\mu \mathrm{M}$ S-(-)-Sulpiride), NK1 (10 $\mu \mathrm{M}$ L-732,138), opioid (10 $\mu \mathrm{m}$ naloxone hydrochloride), nicotinic (100 nм nicotine or $10 \mu \mathrm{M}$ tubocurarine chloride), and muscarinic (25 $\mu \mathrm{M}$ atropine sulfate). Paired recording experiments involving two MSNs were conducted in the presence of $\mathrm{GABA}_{\mathrm{A}}$, opioid and NK1 receptor antagonists. Paired recording experiments from interneuron-MSN pairs were conducted in the presence of $\mathrm{GABA}_{\mathrm{A}}$ receptor antagonists only.

Glutamatergic EPSPs were evoked by electrical stimulation of the corpus callosum (CC), as in previous studies (Blomeley and Bracci, 2011). EPSPs were recorded from MSNs located in the dorsolateral striatum. In all experiments, a single CC stimulus was delivered continuously every $10 \mathrm{~s}$. CC stimulation intensity was adjusted to produce EPSPs of $5-15 \mathrm{mV}$ amplitude. After application of the $\mathrm{GABA}_{\mathrm{B}}$ receptor antagonist CGP 52432, the stimulation protocol continued, but the data acquired in the first 5 min following the start of the application were excluded from the analysis (to include only data acquired when the antagonist concentration had reached a steady state).

In single-recording experiments, every other CC stimulus was preceded by a train of stimuli ( 5 stimuli, $50 \mathrm{~Hz}$ ) delivered by a second stimulator placed in the globus pallidus (GP) to activate antidromically MSN axons (Fig. 1A,B), as previously described (Blomeley and Bracci, $2009,2011)$. This two-protocol cycle was applied without interruption at least 75 times for each pharmacological condition. The CC-evoked responses preceded by GP stimuli were then averaged and compared statistically with those not preceded by GP stimuli. The temporal interval between GP and CC stimulation was calculated from the first GP stimulus of the train to the CC stimulation. In some experiments, two intervals were tested; in this case a three-protocol cycle, comprising (2) no GP stimuli, (2) GP stimuli preceding CC stimulus by interval 1, and (3) GP stimuli preceding CC stimulus by interval 2 , was continuously applied (at least 75 times per pharmacological condition). GP stimulation intensity was adjusted so that no antidromic spike was observed in the recorded MSN (Blomeley et al., 2009).

In paired recording experiments, a MSN and a second GABAergic neuron located within $100 \mu \mathrm{m}$ were recorded simultaneously. Every other CC stimulus was preceded by a train of action potentials ( 5 spikes at $50 \mathrm{~Hz}$ ) elicited by short ( $5 \mathrm{~ms}$ ) current injections in the second neuron (see Fig. 3A), as in previous studies (Blomeley et al., 2009; Blomeley and Bracci, 2011). Again, this two-protocol cycle was applied without interruption at least 75 times for each pharmacological condition. The CCevoked responses preceded by spikes in the other neuron were then averaged and compared statistically with those not preceded by spikes. Intervals were defined as time from the first spike of a burst to the subsequent CC stimulation.

Data were tested using Student's $t$ test; average effects are expressed as mean \pm SEM.

\section{Results}

\section{Antidromic stimulation of MSNs inhibits cortical inputs} onto MSNs

Electrical stimulation of the GP triggers antidromic spikes in both striatonigral and striatopallidal MSNs because the axons of these cells pass through, or terminate, in this region. These antidromic spikes then trigger orthodromic spikes in MSN axon collaterals, causing neurotransmitter release (Guzmán et al., 2003; Blomeley and Bracci, 2009, 2011; López-Huerta et al., 2013). We therefore stimulated the GP to evoke GABA release from MSNs and to test its effect on glutamate responses evoked by CC stimulation (Fig. $1 A, B)$. These experiments were performed in the presence of antagonists for $\mathrm{GABA}_{\mathrm{A}}$, dopamine, opiate, NK1, and acetylcholine receptors (see Materials and Methods) to prevent unwanted activation of these receptors by GP stimulation and MSN firing. An interval (see Materials and Methods) of $500 \mathrm{~ms}$ was chosen, as it had previously been found to maximize opioid-mediated presynaptic inhibition (Blomeley and Bracci, 2011). In juvenile rats, GP stimulation significantly $(p<0.05)$ reduced the amplitude of responses to subsequent CC stimulation in 16/21 neurons (average inhibition $8.6 \pm 0.8 \%$; Fig. $1 C, D$ ). To test whether these effects depended on $\mathrm{GABA}_{\mathrm{B}}$ receptors, in 19 of these experiments (14 of which significant inhibitory effects were observed in control solution) we subsequently applied the specific antagonist CGP $52432(1 \mu \mathrm{M})$, while continuing to apply the same stimulation protocol. In all cases, in the presence of CGP 52432, GP stimulation failed to cause significant inhibition of CC-evoked responses. The effects observed in individual experiments in the absence and in the presence of CGP 52432 are illustrated in the histograms of Figure $1 C$ and in the trend plots of Figure $1 E$. In previous studies, $\mathrm{GABA}_{\mathrm{B}}$ receptor agonists did not cause detectable postsynaptic effects in MSNs, and paired-pulse stimulation experiments pointed to a presynaptic site of action (Calabresi et al., 1992; Nisenbaum et al., 1993). In our experiments, pairedpulse protocols would be difficult to interpret because, unlike the case of bath-applied agonists, $\mathrm{GABA}_{\mathrm{B}}$ receptors are activated transiently by GP stimuli. To test for possible postsynaptic contributions to the effects caused by $\mathrm{GABA}_{\mathrm{B}}$ receptor activation, in some experiments, we applied a $200 \mathrm{~ms}$ negative current step (10-40 pA) $200 \mathrm{~ms}$ after GP stimulation. The membrane potential displacement caused by these steps was measured at the end of the current injection, to minimize the effects of any residual depolarizations induced by the GP stimuli. As illustrated by the example of Figure $1 F$, in $6 / 6$ experiments (in which significant $\mathrm{GABA}_{\mathrm{B}}$ receptor-mediated effects on CC-evoked responses were present), the input resistance was not significantly different when the step was preceded by GP stimuli (on average, $102 \pm 2 \%$ of control).

We concluded that synchronous activation of MSNs caused inhibition of glutamatergic synapses onto MSNs, through GABA release leading to the activation of presynaptic $\mathrm{GABA}_{\mathrm{B}}$ receptors.

\section{Presynaptic inhibition is maximal at $500 \mathrm{~ms}$ interval and disappears at $3 \mathrm{~s}$}

To determine the time course of the inhibition of glutamatergic responses caused by antidromic activation of MSNs, we performed experiments featuring two different time intervals between CC and GP stimulations. These experiments were similar to those described above but consisted of three repeated cycles, one without GP stimulation, one in which GP stimulation preceded CC stimulation by $500 \mathrm{~ms}$ and one in which GP stimulation preceded CC stimulation by either 1,2, or $3 \mathrm{~s}$. Due to the fact that repeated GP stimulation elicited long-tailed glutamatergic 
A

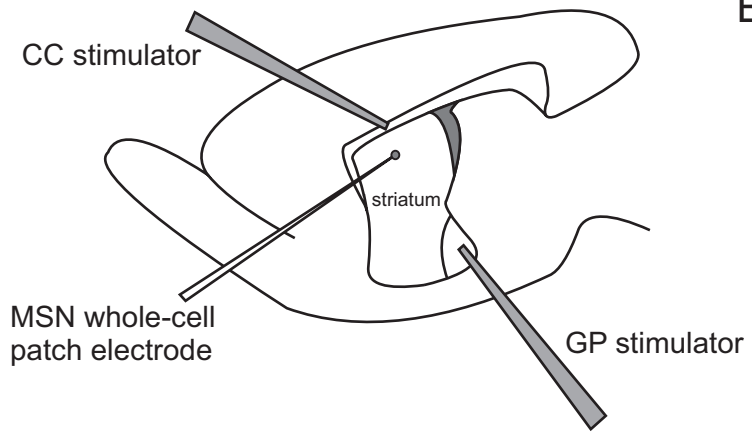

B

protocol 1

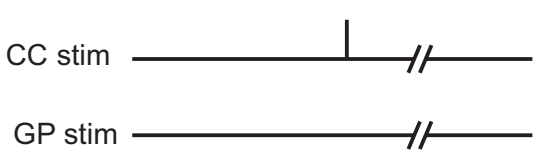

protocol 2

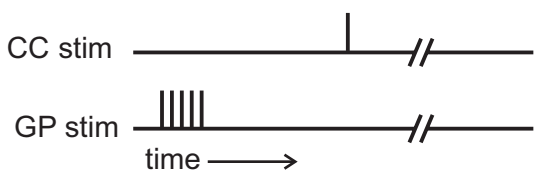

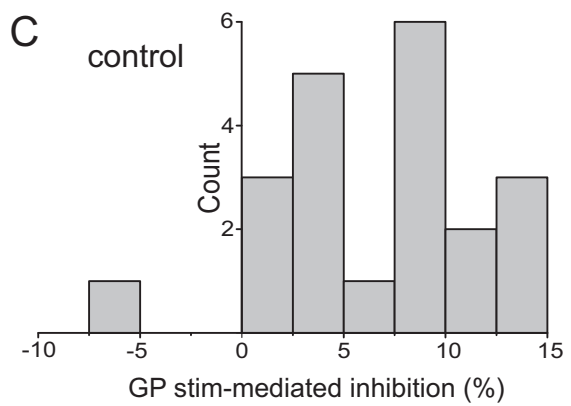
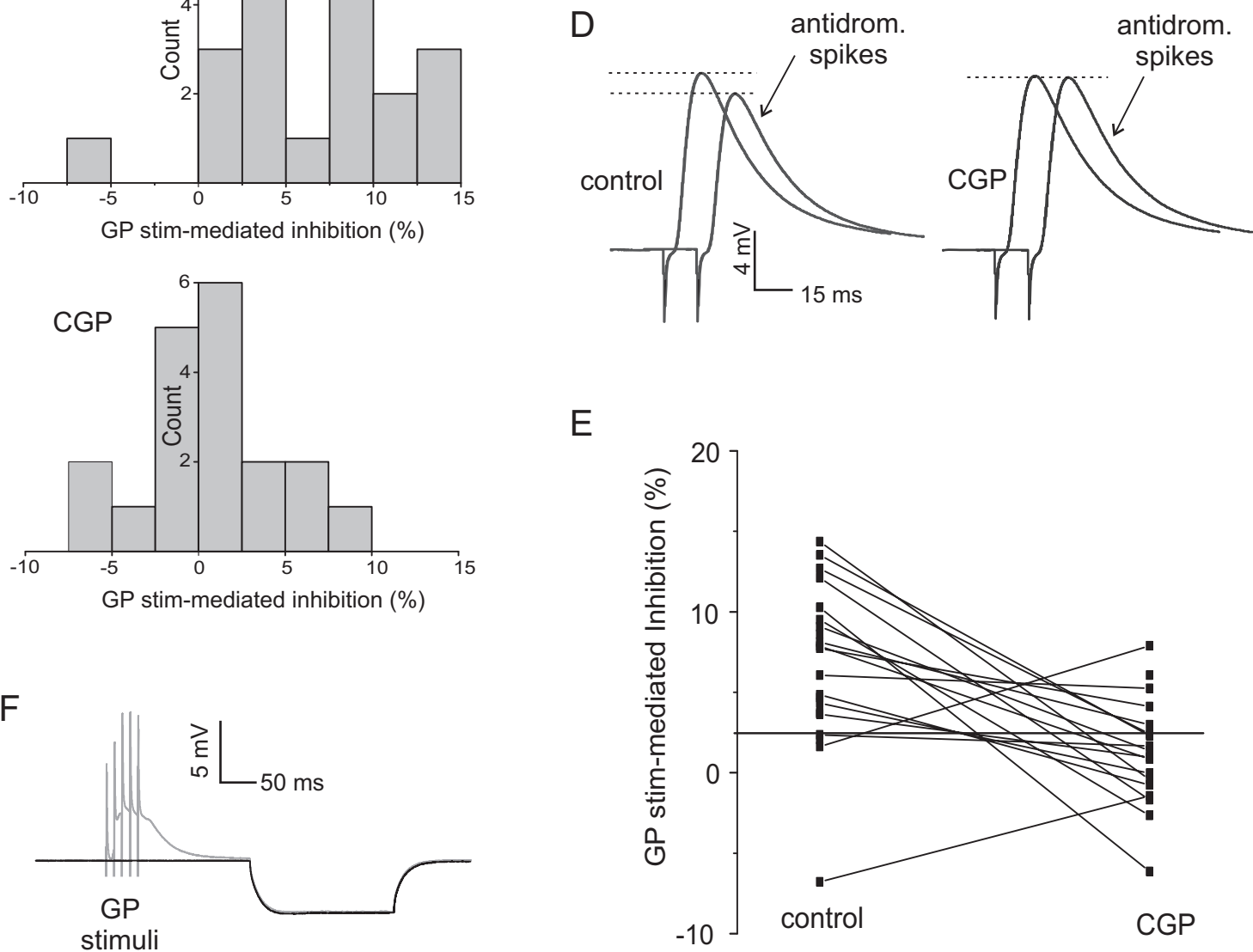

Figure 1. Antidromic activation of MSNs causes $\mathrm{GABA}_{B}$ receptor-dependent inhibition of corticostriatal inputs. $A$, Typical positioning of recording and stimulating electrodes. AMSN was recorded in the dorsolateral striatum. Corticostriatal fibers were activated by electrical stimulation delivered to the CC. MSN axons were antidromically activated by electrical stimulation delivered to the GP. B, Stimulation sequence. Two consecutive stimulation protocols (each lasting $10 \mathrm{~s}$ ) were continuously applied. In the first one, a single stimulation to the CC evoked control responses in the MSN. In the second protocol the $C($ stimulation was preceded (by $0.5 \mathrm{~s}$ ) by a train of five stimuli in the GP, to elicit GABA release from a population of MSNs. This two-protocol cycle was applied without interruptions at least 75 times for each pharmacological condition. C, Distribution of the average inhibitory effects of MSN antidromic activation on cortically evoked EPSPs observed in 21 experiments in control solution (top) and in the presence of (GP 52432 (bottom). D, GABA ${ }_{B}$ receptor-mediated inhibition in a representative experiment. Traces are averages of CC-evoked responses without or with preceding GP stimulation. In control solution, cortical inputs are inhibited by preceding antidromic activation of MSNs. In the presence of CGP 52432 , these inhibitory effects are abolished. $\boldsymbol{E}$, Inhibitory effects of antidromic MSN stimulation on cortical responses in individual experiments. In each case, CGP 52432 was applied after the stimulation protocols had been performed in control solution. $\boldsymbol{F}$, A representative example of the lack of effects of GP stimuli on MSN input resistance. The trace in black is the average of 90 consecutive steps ( $200 \mathrm{~ms}$, $-30 \mathrm{pA}$ ) applied without preceding GP stimuli. The gray trace is the average of 90 consecutive steps ( $200 \mathrm{~ms},-30 \mathrm{pA}$ ) applied $200 \mathrm{~ms}$ after the GP stimuli. Current steps were delivered every $10 \mathrm{~s}$ and GP stimuli preceded every other step.

responses in MSNs, it was not technically possible to test intervals smaller than 500 ms (Blomeley et al., 2009; Blomeley and Bracci, 2011). In all experiments, the inhibitory effects were larger for $500 \mathrm{~ms}$ intervals than for the other interval tested. In 14/14 of these experiments, significant $(p<0.05)$ inhibitory effects were observed at $500 \mathrm{~ms}$ intervals; at $1 \mathrm{~s}$ intervals, significant inhibition was observed in $4 / 4$ experiments. At $2 \mathrm{~s}$ intervals, significant inhibition was observed in $2 / 4$ experiments. At $3 \mathrm{~s}$ intervals, no significant 
inhibition was observed in six experiments. The results observed in each experiment are illustrated in Figure $2 A$. In 12 of these experiments, CGP 52432 was subsequently added. In the presence of CGP5242, no significant inhibition was present for $500 \mathrm{~ms}$ intervals in 11/12 experiments and in 12/12 experiments for longer time intervals (1-3 s). A representative experiment in which two intervals were tested is illustrated in Figure $2 B$.

\section{GABA released by single NGFIs but not other GABAergic neurons inhibits cortical glutamate release}

In addition to MSNs, GABA is released by three well characterized types of interneurons in the striatum: LTSI, FSI, and NGFI. We therefore investigated whether individual GABAergic neurons were capable of suppressing cortically evoked glutamate release onto MSNs by activating $\mathrm{GABA}_{\mathrm{B}}$ receptors. This was accomplished with paired recording experiments, in which a MSN and another striatal GABAergic neuron (located $<100 \mu \mathrm{m}$ apart in the dorsolateral striatum) were recorded simultaneously (Fig. $3 A$ ). In these experiments, every other CC stimulation was preceded by five spikes evoked in the GABAergic neuron (see Materials and Methods). The interval between the first spike and the CC stimulus was $500 \mathrm{~ms}$ for all the experiments. The two consecutive stimulation protocols used are illustrated in Figure 3B. In each individual experiment out of a total of 57 MSN-MSN and 7 FSI-MSN paired recordings (performed in rats), spikes in a neighboring neuron (either another MSN or a FSI) failed to affect the CC-evoked responses of MSNs significantly (on average, responses preceded by spikes in another MSN were $101 \pm 2 \%$ of control, whereas those preceded by spikes in a FSI were $99 \pm 2 \%$ of control). We also performed 24 LTSI-MSN paired recordings using NPYreporting BAC mice (Fig. 3C; see Materials and Methods for details). In each individual experiment, spikes in the LTSIs failed to significantly affect the CC-evoked responses of the simultaneously recorded MSNs (on average, responses preceded by spikes in an LTSI were $100 \pm 1 \%$ of control). Examples of the absence of effects of spikes in a neighboring LTSI or an FSI on MSN responses are shown in Figure 3D.

We concluded that a burst of spikes in individual MSNs, FSIs, or LTSIs is not sufficient to elicit $\mathrm{GABA}_{\mathrm{B}}$ receptor-dependent inhibition of glutamatergic responses of a neighboring MSN. A novel striatal GABAergic interneuronal type, termed neurogliaform interneuron, has been recently described (Ibáñez-Sandoval et al., 2011). These interneurons also express NPY, have distinctive electrophysiological properties (Fig. 3E), and elicit large, long-lasting GABAergic IPSPs in MSNs (English et al., 2012). Therefore, we used paired recordings from NGFI-MSN pairs in $\mathrm{BAC}$ mice to test for their ability to cause $\mathrm{GABA}_{\mathrm{B}}$ receptormediated inhibition of glutamate responses.

In contrast to the other GABAergic neurons tested, we found that in 5/11 NGFI-MSN paired recording experiments, spikes in the NGFI significantly inhibited subsequent CC-evoked responses in MSNs $(p<0.05$; Fig. $3 F, G)$. On average, in these five cases, EPSP inhibition induced by NGFI spikes was $4.1 \pm 0.3 \%$.

In seven of these experiments, including all cases in which significant effects were observed in control solution, CGP 52432 was subsequently applied, abolishing any NGFImediated inhibition (Fig. $3 F, G$ ). We concluded that NGIs are the only GABAergic neurons in the striatum capable of individually triggering $\mathrm{GABA}_{\mathrm{B}}$ receptors-mediated inhibition of glutamate responses through a burst of spikes.

\section{Discussion}

The main finding of this study is that endogenous GABA, released by either a population of striatal MSNs or an individual NGFI, can depress glutamatergic inputs to MSNs by activating $\mathrm{GABA}_{\mathrm{B}}$ receptors. Conversely, individual MSNs, FSIs, or LTSIs did not elicit detectable $\mathrm{GABA}_{\mathrm{B}}$ receptor-mediated effects under the conditions of this study.

Our paired recording experiments clearly showed that a burst of five spikes in a single MSN was never able to produce significant $\mathrm{GABA}_{\mathrm{B}}$ receptor-mediated inhibition of glutamatergic inputs to a neighboring MSN. In contrast, such inhibition could be easily elicited by activating a population of MSNs with five antidromic stimuli delivered at the same frequency. This protocol excites similar numbers of striatopallidal and striatonigral MSNs, eliciting orthodromic spikes in their axon collaterals and synchronous release of GABA (López-Huerta et al., 2013). The most 
A

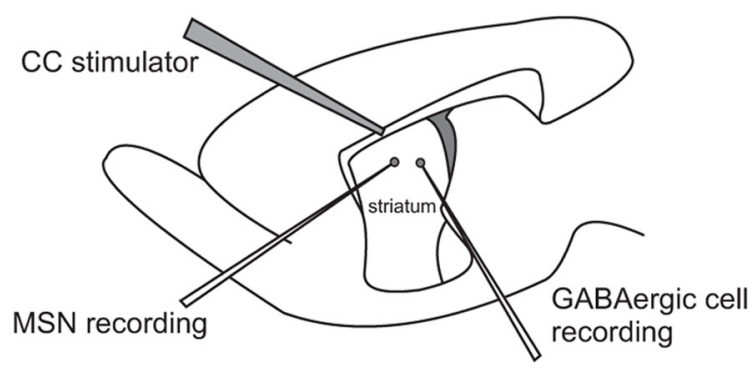

C

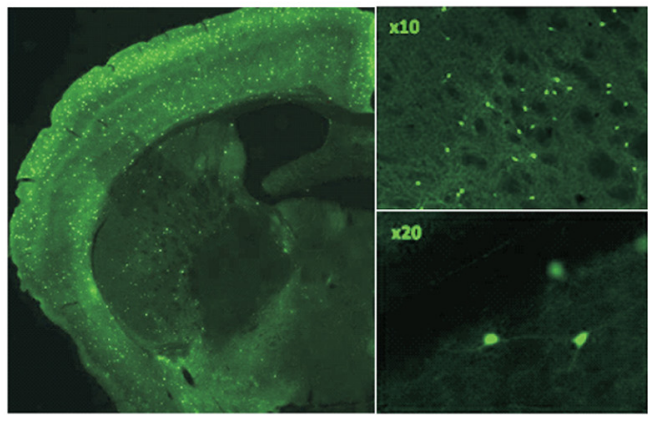

E

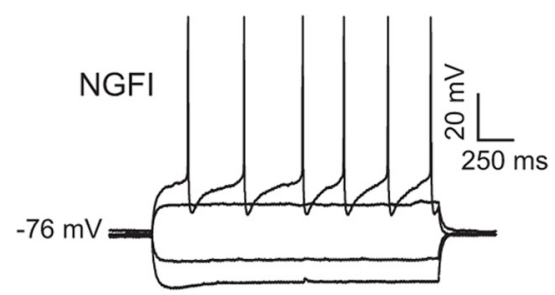

F
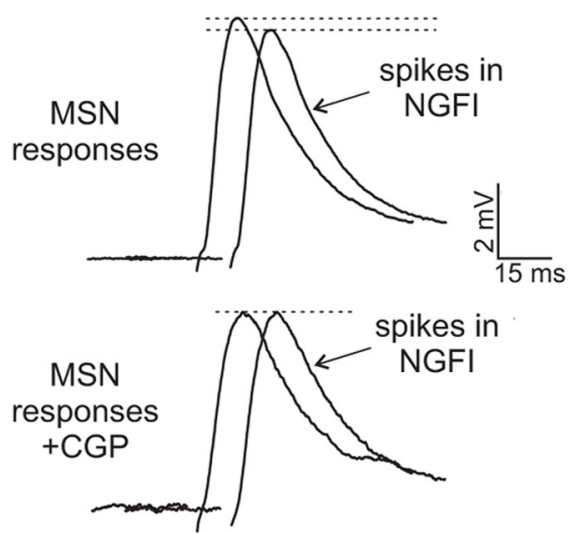

B

protocol 1

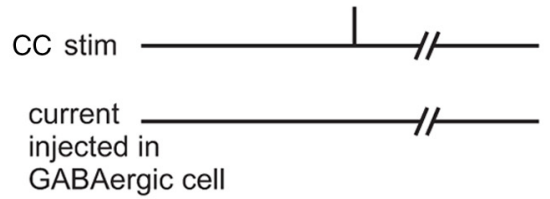

protocol 2

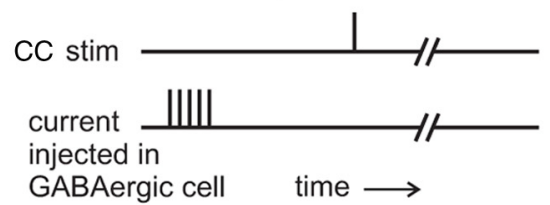

D

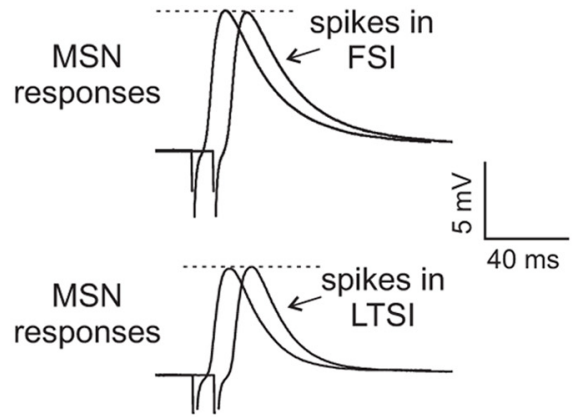

G
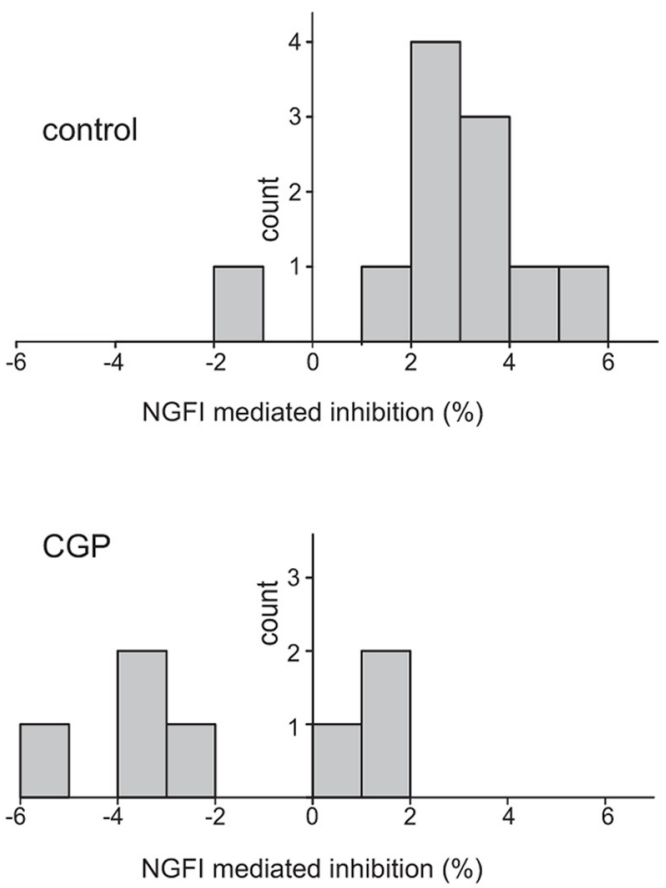

Figure 3. Individual NGFls inhibit corticostriatal responses via $G_{A B A}$ receptors. $A$, Positioning of recording and stimulating electrodes in dual recording experiments. $A M S N$ and a second $G A B A$ ergic neuron were recorded in the dorsolateral striatum. The distance between the two recorded cells was $<100 \mu \mathrm{m}$. Corticostriatal fibers were activated by stimulation in the CC. B, Stimulation sequence. Similar to Figure $1 B$, two stimulation protocols were applied consecutively. In the first protocol (10 s duration) a single CC stimulus was delivered. In the second protocol (bottom, $10 \mathrm{~s}$ duration), a single CC stimulation was preceded by five short $(5 \mathrm{~ms})$ depolarizing current pulses in the GABAergic cell, each of which elicited one action potential. This two-protocol cycle was applied without interruptions at least 75 times for each pharmacological condition. C, Coronal slice image of GFP fluorescence from NPY-GFP-expressing BAC transgenic mice. In the striatum, GFP-expressing neurons are either LTSIs or NGFIs. D, Two representative examples of the lack of effects of spikes of FSIs and LTSIs on the CC-evoked responses of neighboring MSNs. In the FSI-MSN experiment (top), each trace is the average of the MSN responses to a CC stimulus either preceded (right) or not preceded (left) by spikes in the FSI. In the LTSI-MSN experiment (bottom, different animal), each trace is the average of MSN responses either preceded (right) or not preceded (left) by spikes in the LTSI. $\boldsymbol{E}$, Typical electrophysiological properties of a NGFI revealed by negative and positive current pulses. Note large, slow spike-afterhyperpolarizations. $\boldsymbol{F}$, Average traces from a representative experiment. In control solution, MSN responses to CC stimulation were significantly $(p<0.05)$ inhibited by preceding NGFl action potentials. In CGP 52432 , this inhibition was abolished. G, Distribution of the inhibitory effect of NGFI action potentials on cortical responses of MSNs from 11 experiments in control solution (top), 7 of which lasted enough for subsequent application of (GP 52432 (bottom). 
likely explanation for these results is therefore that a relatively large amount of GABA needs to be released to activate presynaptic $\mathrm{GABA}_{\mathrm{B}}$ receptors located on glutamatergic afferent. MSNMSN GABAergic synapses tend to be formed on the dendritic shafts, whereas corticostriatal glutamatergic inputs are mainly formed on dendritic spines (Boyes and Bolam, 2007). Therefore, activation of presynaptic $\mathrm{GABA}_{\mathrm{B}}$ receptors located on glutamatergic terminals requires substantial diffusion of GABA in the extrasynaptic space. Apparently, this took place effectively only when a number of MSNs were synchronously activated. GP stimulation causes antidromic activation of both striatopallidal and striatonigral MSNs, but it does not allow precise identification of the size of the stimulated MSN population. A pallidostriatal GABAergic projection has been demonstrated, but it targets selectively striatal interneurons rather than MSNs (Bevan et al., 1998) and therefore it is unlikely to have played a role in the observed phenomenon.

Although we did not demonstrate directly that the present effects of $G_{A B A}$ receptors were presynaptic, previous experiments performed with exogenous agonists strongly suggest that this was the case. Indeed, application of $\mathrm{GABA}_{\mathrm{B}}$ receptor agonists has been shown to reduce glutamatergic EPSPs of MSNs through a presynaptic mechanisms, whereas no postsynaptic effects were observed (Calabresi et al., 1991; Nisenbaum et al., 1993). This is somehow puzzling, as $\mathrm{GABA}_{\mathrm{B}}$ receptors are found postsynaptically on MSNs (Lacey et al., 2005). Consistent with the previous electrophysiological experiments, we never observed $\mathrm{GABA}_{\mathrm{B}}$ receptor-mediated postsynaptic effects caused by spikes in MSN populations or individual NGFIs. Further studies will be required to reveal whether postsynaptic $\mathrm{GABA}_{\mathrm{B}}$ receptors are functionally impaired, or alternatively, mediate effects that are not detected by standard electrophysiological techniques.

In this study, glutamatergic responses were evoked by electrical stimulation of the portion of CC located between the cortex and the striatum. Although this procedure can be expected to produce preferential activation of corticostriatal fibers, it is likely that some thalamostriatal axons were also activated. Presynaptic $\mathrm{GABA}_{\mathrm{B}}$ receptors are found on both corticostriatal and thalamostriatal terminals (Lacey et al., 2005). Further studies will be required to establish whether specific features of $G_{A B A}-$ mediated inhibition differ in the two sets of afferents.

The present results complement our previous findings that different populations of MSNs control the glutamatergic terminals in opposite ways either through activation of presynaptic NK1 receptors by substance $\mathrm{P}$, or of presynaptic $\mu$-opioid receptors by enkephalin (Blomeley et al., 2009; Blomeley and Bracci, 2011).

The time course of $\mathrm{GABA}_{B}$ receptor-mediated inhibitory effects is similar to that observed for the activation of $\mu$-opioid receptors (Blomeley and Bracci, 2011). In that case, inhibition of glutamate inputs was found to peak $500 \mathrm{~ms}$ after a burst of spike and to be still present, although reduced, after $1 \mathrm{~s}$, and in some cases, after $2 \mathrm{~s}$. This is slower than substance P-mediated facilitation, that was found to peak after $250 \mathrm{~ms}$ (Blomeley and Bracci, 2011). The different time course of facilitatory and inhibitory presynaptic interactions is likely to give rise to specific network dynamics that may be key to the striatal function.

An important difference between the previously studied presynaptic interactions and those mediated by $\mathrm{GABA}_{\mathrm{B}}$ receptors is that the former could be elicited by spikes in individual MSNs. In the case of GABA acting on $\mathrm{GABA}_{\mathrm{B}}$ receptors, the effects require synchronous activation of several MSNs. On the other hand, individual NGFIs, that do not express substance P or enkephalin, were capable of activating presynaptic $\mathrm{GABA}_{\mathrm{B}}$ receptors. These neurons, that were recently discovered, elicit large and longlasting $\mathrm{GABA}_{\mathrm{A}}$ receptor-mediated IPSPs in MSNs (IbánezSandoval et al., 2011; English et al., 2012), consistent with a strong release of GABA from their terminals. The present results show that they also cause an even slower presynaptic inhibition of the excitatory inputs to MSNs. Although the effects caused by spikes in a single NGFI were relatively small, many such interneurons are in the position to affect the input to an MSN (IbáñezSandoval et al., 2011); furthermore, the all-or-none nature of spike generation means that the ability of a glutamatergic input to drive an MSN above threshold may be impaired even by a small reduction in its amplitude. Thus, NGFIs are in a position to exert a strong influence on the local striatal circuits. It will be important from a functional point of view to determine the nature of the glutamatergic inputs that these interneurons receive from the cortex and the thalamus. Importantly, spikes in individual cholinergic interneurons also cause presynaptic inhibition of glutamatergic inputs to MSN (Pakhotin and Bracci, 2007; Ding et al., 2010).

Collectively, these observations provide a novel picture of the striatal network, in which rapid feedforward and feedback GABAergic inhibition through ionotropic $\mathrm{GABA}_{\mathrm{A}}$ receptors is accompanied by slower presynaptic metabotropic interactions mediated by peptides, GABA, and acetylcholine. It is tempting to speculate that these presynaptic interactions, whether facilitatory (substance $\mathrm{P}$ ) or inhibitory (enkephalin, acetylcholine, and GABA), will create a grid of primed or suppressed synapses after an initial barrage of cortical inputs. This may be an effective way to create dynamic cell assemblies, particularly prone to be excited by further cortical inputs, whereas other groups of projection neurons are denied access to cortical excitation. Computational models will be useful to explore how these presynaptic interactions affect action selection and reinforcement learning in the striatum.

\section{References}

Alexander GE, Crutcher MD (1990) Functional architecture of basal ganglia circuits: neural substrates of parallel processing. Trends Neurosci 13:266271. CrossRef Medline

Bevan MD, Booth PA, Eaton SA, Bolam JP (1998) Selective innervation of neostriatal interneurons by a subclass of neuron in the globus pallidus of the rat. J Neurosci 18:9438-9452. Medline

Blomeley CP, Bracci E (2009) Serotonin excites fast-spiking interneurons in the striatum. Eur J Neurosci 29:1604-1614. CrossRef Medline

Blomeley CP, Bracci E (2011) Opioidergic interactions between striatal projection neurons. J Neurosci 31:13346-13356. CrossRef Medline

Blomeley CP, Kehoe LA, Bracci E (2009) Substance P mediates excitatory interactions between striatal projection neurons. J Neurosci 29:49534963. CrossRef Medline

Bolam JP, Hanley JJ, Booth PA, Bevan MD (2000) Synaptic organisation of the basal ganglia. J Anat 196:527-542. CrossRef Medline

Boyes J, Bolam JP (2007) Localization of GABA receptors in the basal ganglia. Prog Brain Res 160:229-243. CrossRef Medline

Bracci E, Centonze D, Bernardi G, Calabresi P (2003) Voltage-dependent membrane potential oscillations of rat striatal fast-spiking interneurons. J Physiol 549:121-130. CrossRef Medline

Calabresi P, Mercuri NB, De Murtas M, Bernardi G (1991) Involvement of GABA systems in feedback regulation of glutamate-and GABA-mediated synaptic potentials in rat neostriatum. J Physiol 440:581-599. Medline

Calabresi P, Mercuri NB, Stefani A, Bernardi G (1992) Physiological role of GABAb receptors in the mammalian neostriatum. Adv Biochem Psychopharmacol 47:217-221. Medline

Chalifoux JR, Carter AG (2011) GABAB receptor modulation of synaptic function. Curr Opin Neurobiol 21:339-344. CrossRef Medline

Ding JB, Guzmán JN, Peterson JD, Goldberg JA, Surmeier DJ (2010) Tha- 
lamic gating of corticostriatal signaling by cholinergic interneurons. Neuron 67:294-307. CrossRef Medline

English DF, Ibáñez-Sandoval O, Stark E, Tecuapetla F, Buzsáki G, Deisseroth K, Tepper JM, Koos T (2012) GABAergic circuits mediate the reinforcement-related signals of striatal cholinergic interneurons. Nat Neurosci 15:123-130. CrossRef Medline

Graybiel AM, Aosaki T, Flaherty AW, Kimura M (1994) The basal ganglia and adaptive motor control. Science 265:1826-1831. CrossRef Medline

Guzmán JN, Hernandez A, Galarraga E, Tapia D, Laville A, Vergara R, Aceves J, Bargas J (2003) Dopaminergic modulation of axon collaterals interconnecting spiny neurons of the rat striatum. J Neurosci 23:8931-8940. Medline

Ibáñez-Sandoval O, Tecuapetla F, Unal B, Shah F, Koós T, Tepper JM (2011) A novel functionally distinct subtype of striatal neuropeptide $\mathrm{Y}$ interneuron. J Neurosci 31:16757-16769. CrossRef Medline

Lacey CJ, Boyes J, Gerlach O, Chen L, Magill PJ, Bolam JP (2005) GABA(B) receptors at glutamatergic synapses in the rat striatum. Neuroscience 136: 1083-1095. CrossRef Medline

López-Huerta VG, Carrillo-Reid L, Galarraga E, Tapia D, Fiordelisio T, DruckerColin R, Bargas J (2013) The balance of striatal feedback transmission is disrupted in a model of parkinsonism. J Neurosci 33:4964-4975. CrossRef Medline
Nisenbaum ES, Berger TW, Grace AA (1993) Depression of glutamatergic and GABAergic synaptic responses in striatal spiny neurons by stimulation of presynaptic GABAB receptors. Synapse 14:221-242. CrossRef Medline

Pakhotin P, Bracci E (2007) Cholinergic interneurons control the excitatory input to the striatum. J Neurosci 27:391-400. CrossRef Medline

Partridge JG, Janssen MJ, Chou DY, Abe K, Zukowska Z, Vicini S (2009) Excitatory and inhibitory synapses in neuropeptide Y-expressing striatal interneurons. J Neurophysiol 102:3038-3045. CrossRef Medline

Szydlowski SN, Pollak Dorocic I, Planert H, Carlén M, Meletis K, Silberberg G (2013) Target selectivity of feedforward inhibition by striatal fast-spiking interneurons. J Neurosci 33:1678-1683. CrossRef Medline

Tepper JM, Bolam JP (2004) Functional diversity and specificity of neostriatal interneurons. Curr Opin Neurobiol 14:685-692. CrossRef Medline

Tepper JM, Wilson CJ, Koós T (2008) Feedforward and feedback inhibition in neostriatal GABAergic spiny neurons. Brain Res Rev 58:272-281. CrossRef Medline

Tunstall MJ, Oorschot DE, Kean A, Wickens JR (2002) Inhibitory interactions between spiny projection neurons in the rat striatum. J Neurophysiol 88:1263-1269. Medline 